\title{
PROPOSTA DE UM MODELO DE COLETA PARA O CANAL REVERSO DE PÓS CONSUMO DE PAPEL EM UM CAMPUS UNIVERSITÁRIO BASEADO NA TEORIA DOS GRAFOS
}

\author{
COLLECT MODEL TO THE PAPER' REVERSE CHANNEL IN AN \\ BRAZILIAN FEDERAL UNIVERSITY BASED IN THEORY OF GRAPHS
}

\author{
Francisco Firmino da Silva Neto* E-mail: firmino f@yahoo.com \\ Breno Barros Telles do Carmo*E-mail: brenotelles@hotmail.com \\ *Universidade Federal Rural do Semi Árido (UFERSA), Mossoró, RN
}

\begin{abstract}
Resumo: As universidades devem desenvolver e promover formas de reduzir, reutilizar e reciclar materiais utilizados em suas atividades, de forma a minimizar impacto ao meio ambiente. Dentre os materiais recicláveis, o papel pós-consumo é um resíduo comum a este tipo de organização e pode ser utilizado em processos de reciclagem, desde que existam canais logísticos reversos para coleta e destinação deste material. Neste sentido, o presente artigo tem como objetivo propor um modelo de coleta para o papel pós-consumo gerado pelas unidades administrativas do campus de uma universidade federal baseado na Teoria dos Grafos. Para tanto, foi realizada uma pesquisa exploratória para obter a estimativa de geração do material para, em seguida, propor um modelo para definir uma rota para a coleta de material conforme a alocação de ecopontos, minimizando os tempos totais de coleta. Observou-se que o modelo se mostrou eficiente, reduzindo os tempos de coleta do material em cerca de $30 \%$. Este modelo possui caráter genérico e servirá de base para que outras entidades possam aplicá-lo.
\end{abstract}

Palavras-chave: Logística reversa. Papel. Universidade. Teoria dos grafos.

Abstract: The universities must develop models to reduce, reutilize and recycle the material used in their activity, in order to minimize the impact to environment. The paper is a residue is this type of organization and can be used at the recycling process, but is necessary the existence of the reverse logistics channels to collect this material. This paper aims the proposition of a model to collect the paper generated inside the campus of a federal university of Brazil based on the Graph Theory. An exploratory research was done to get an estimation of the quantity of material generated. After this, a model was proposed to define a route to material collection based in collect points, minimizing the time waste in this process. The model is efficient and reduced thirty percent the time of the collect process. This model can be used to other universities.

Keywords: Reverse logistics. Paper. University. Theory of Graphs.

\section{INTRODUÇÃO}

A logística reversa de produtos pós-consumo ou pós-venda tem ganhado importância em função da atenção dispendida da sociedade para este tema. Assim, 
as empresas passaram a dar mais ênfase a esta questão, tendo em vista a oportunidade de gerar uma vantagem competitiva (SOUZA \& FONSECA, 2008).

Nas empresas, a implantação deste conceito tem como principal objetivo estratégico a agregação de valor econômico. No entanto, observa-se o surgimento de dois novos fatores que estimulam decisões empresariais na sua adoção (DIAS, 2006):

- O primeiro está relacionado competitividade, com intuito da fidelização do consumidor;

- O segundo relaciona-se à conscientização ecológica oriunda do conceito de sustentabilidade, que tem por objetivo fazer com que as cargas ambientais dos processos e produtos não ultrapassem a capacidade de carga natural do meio ambiente, tendo em vista a imposição pública e governamental para que se reduzam os diversos impactos ambientais de suas atividades, processos e produtos.

Um dos produtos que representa impacto ambiental e é alvo de constantes campanhas de conscientização é o papel. O consumo de papel tem aumentado seis vezes mais no mundo inteiro, segundo dados do Worldwatch Institute (IDEC, 2008) e, consequentemente, a necessidade de retirada de recursos naturais é cada vez maior para alimentar o processo produtivo. Vale ressaltar que, para produzir cinquenta quilos de papel, é necessário o corte de uma árvore, além da grande quantidade de água, energia e produtos químicos tóxicos utilizados no procedimento (IDEC, 2008).

Uma das fontes de consumo de papel são as instituições de ensino superior. Como parte integrante deste contexto encontra-se a Instituição Federal de Ensino Superior (IFES) objeto deste estudo, localizada no município de Mossoró, no estado do Rio Grande do Norte, onde a média mensal de consumo de papel é de 192,8 resmas (aproximadamente 451,1 kg), o equivalente ao corte de 13 (treze) árvores por mês. Observa-se ainda o aumento do consumo desse material, que pode ser atrelado à fase de crescimento em infraestrutura e geração de conhecimento (criação de novos cursos e unidades geradoras) que a universidade está passando. Entretanto, a instituição não possui um sistema de coleta de papel estruturado, realizando de forma empírica o processo de coleta deste material, o que resulta em 
um mau aproveitamento dos recursos de mão de obra e equipamentos. Assim, o escopo deste trabalho relaciona-se com a forma de otimizar o processo e os meios de como o descarte deste material é realizado.

Neste sentido, este trabalho tem como objetivo propor um modelo de roteirização que aperfeiçoe o processo de logística reversa na IFES no tocante a coleta e destinação adequada do papel de pós-consumo para um centro de reciclagem localizada dentro de suas instalações.

Este artigo está estruturado em cinco tópicos: o primeiro apresenta a introdução, o segundo aborda a revisão de literatura, contendo os conceitos de logística reversa e teoria dos grafos, o terceiro ilustra a metodologia desenvolvida no estudo, o quarto mostra o caso estudado e o quinto apresenta as conclusões obtidas com este estudo.

\section{REVISÃO DE LITERATURA}

\subsection{Logística reversa}

Logística pode ser definida como a união de quatro atividades básicas: aquisição, movimentação, armazenagem e entrega de produtos (DIAS, 1996). Neste sentido, Novaes (2001) entende que a realização conjunta destas quatro atividades com foco na estratégia competitiva da empresa representa um sistema de fluxo dos materiais entre as organizações e os consumidores.

A partir dos anos 70, o fluxo inverso de produtos e materiais passou a ser objeto de estudo, sendo criados os termos "canal reverso" e "fluxo reverso" (Guiltian \& Nwokoye, 1974). Leite (2009) afirma que, nas décadas de 1970 e 1980, foram realizados os primeiros estudos sobre logística reversa, voltada principalmente para retorno de bens a serem processados e a reciclagem de matérias, denominados e analisados como canais de distribuição reversos.

Dentro deste contexto, Bai e Sarkis (2013) entendem que as atividades de gestão de estoques com foco na minimização do desperdício e as atividades de transporte relacionadas à destinação dos resíduos são algumas das principais funções da logística reversa apresentadas na literatura. 
Entretanto, outros autores, como Aitken e Harrison (2013), observam que a função da logística reversa é gerar valor de modo que seja viável a reutilização/reciclagem dos produtos de uma cadeia de suprimentos. Ambos os autores entendem que, de fato, a logística reversa funciona como uma ferramenta que colabora com a promoção da sustentabilidade, tema este que tem ganhado projeção nos últimos anos.

Neste sentido, a logística reversa tem ganhado uma importância significativa para a literatura e a sociedade. Esse crescente interesse está associado à consolidação do conceito de desenvolvimento sustentável, representado pela preocupação da sociedade com questões ambientais.

Com isso, surge a necessidade de uma visão mais ampla e a integração da sustentabilidade na cadeia de valor, com uma correta destinação dos resíduos oriundos da atividade econômica. Neste sentido, determinar a destinação dos resíduos é algo primordial para a promoção da sustentabilidade da cadeia (KIPPER, MÄHLMANN e RODRIGUEZ, 2009). Corroborando com esta ideia, Sellito et. al. (2013) entendem que "o gerenciamento dos retornos é a parte da gestão da cadeia de suprimentos que inclui a busca, seleção, coleta, organização da carga, transporte de retorno e descarga".

Por outro lado, as empresas buscam reduzir o impacto negativo de sua atividade no meio ambiente, visando atender às legislações ambientais, como também comunicar seu público uma imagem de empresa cidadã consciente da sua responsabilidade socioambiental perante a comunidade (CHAVES \& ALCÂNTARA, 2009).

Assim, a sustentabilidade altera o cenário competitivo, obrigando as empresas a analisar de forma diferente os seus produtos, processos e modelos de negócio (GABRIELE et al., 2012).

Além do marketing proporcionado por ações relacionadas à logística reversa, existem ainda as imposições legais, como a Política Nacional de Resíduos Sólidos (PNRS). Godoy (2013) entende que esta política é um mecanismo legal, que contém aspectos genéricos com o objetivo de apontar orientações relativas à gestão de resíduos. O mesmo autor considera um desafio a implantação desta política, dados os custos associados às ações de gestão dos resíduos. Assim, as ferramentas de 
otimização podem ser um instrumento útil para otimizar os recursos e reduzir os custos inerentes a estas atividades.

A definição de logística reversa vem evoluindo ao longo do tempo. Inicialmente, representava um simples fluxo em direção contrária. Posteriormente, passou a englobar os aspectos relacionados às questões ambientais e volta aos pilares originais do conceito (DEKKER et al., 2004).

A logística reversa inclui todas as atividades mencionadas nas definições anteriores, com a diferença que o fluxo de operações é tratado no sentido inverso. Ou seja, a logística reversa é definida como processo que planeja, implementa e controla a eficácia e eficiência do fluxo de estocagem de mercadorias, serviços e informações relacionadas desde do ponto de consumo até o ponto de origem, com objetivo de recuperar valor ou descartar de forma adequada do produto (ROGERS \& TIBBEN-LEMBKE, 1998).

Além disso, Sellito et al. (2013) entendem que a logística reversa está incorporado como uma das categorias da Gestão Verde da Cadeia de Suprimentos (Green Supply Chain Management).

Em resumo, a Logística Reversa trabalha nos fluxos de materiais que se iniciam nos pontos de consumo dos produtos e terminam nos pontos de origem, com o objetivo de recapturar valor ou de disposição final adequado, ou não.

Os canais de distribuição reversos tem sido alvo de preocupação estratégica das empresas, do governo e da sociedade. Estes canais englobam ações como ampliação do ciclo de vida (reutilização) e retorno (reciclagem) destes bens após o término de sua função para o ciclo produtivo, readquirindo valor no mesmo mercado original ou secundário, sendo reaproveitados seus componentes ou materiais constituintes (LEITE, 2009).

Os canais de distribuição reversos podem ser classificados em dois tipos (LEITE, 2009). O primeiro é formado pelos canais reversos de pós-consumo. Neste caso, os produtos têm vida útil variável, mas após um tempo de utilização, perdem suas características básicas de funcionamento e tem de ser descartados. O segundo tipo é formado pelos canais de distribuição reversos de pós-venda. Neste caso, inclui-se o retorno de embalagens e retorno de produtos ao varejista ou ao fabricante. 
Nesta pesquisa, o canal de distribuição reverso enfatizado será o fluxo de bens pós-consumo, tendo em vista a disposição adequada e reciclagem do papel inservível gerado pelas unidades IFES estudada.

A logística reversa com ênfase nos bens pós-consumo, torna-se uma ferramenta importante para implantação de programas de produção e consumo sustentáveis, visto que a logística sob o enfoque na recuperação de produtos pósconsumo pode ser considerado um instrumento de gestão ambiental (BARBIERI \& DIAS, 2002).

A Figura1 sintetiza as duas categorias de canais de distribuição reversos de pós-venda e de pós-consumo.

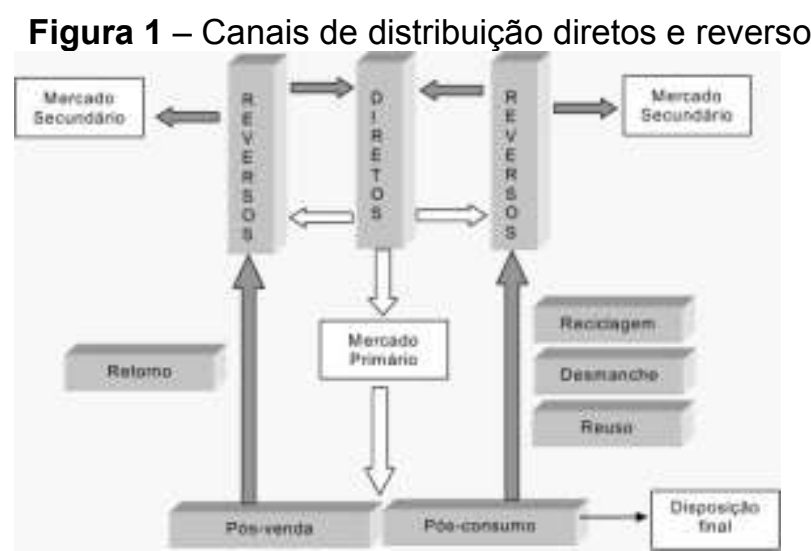

Fonte: Leite (1999)

Na Figura 1, o fluxo dos produtos nos canais de distribuição diretos, desde as matérias-primas primárias (virgens) até o mercado é denominado como o mercado primário dos produtos. Há diversas possibilidades de se processar o fluxo direto dos produtos, conhecidos como as etapas de atacadista ou distribuidores, logo depois aos varejistas e, por fim, chegando aos consumidores finais (LEITE, 2009).

Os canais de distribuição reversos de pós-consumo e pós-venda apresentam características diferentes do fluxo direto, já que a estruturação do canal reverso considera que o fluxo é caracterizado por pequenos volumes de itens diferentes com frequência irregular (GUARNIERI, 2011). Os canais de distribuição reversos de pósconsumo (CDR-PC) são formados pelo fluxo reverso de uma parcela de produtos e de materiais constituintes originados no descarte de produtos depois de finalizada sua utilidade original, retornando de alguma maneira, ao ciclo produtivo (LEITE, 2009).

Revista Produção Online, Florianópolis, SC, v.13, n. 4, p. 1543-1568, out./dez. 2013. 
A grande questão neste ponto é definir uma forma economicamente eficiente para realizar tal atividade logística. Nesse sentido, existem as ferramentas de otimização que podem servir de base para encontrar as soluções com menor custo. Neste artigo será apresentada uma ferramenta que visa identificar a o caminho com menor custo, aqui representado pelo caminho mínimo.

\subsection{Teoria dos Grafos}

A teoria dos grafos é uma ferramenta fundamental a gestão de recursos, planejamento de transporte e otimização de recursos humanos, sendo aplicados a diversos problemas, como problemas de localização e de traçado de rotas para diversos tipos de serviços, estudo da estrutura do DNA e projetos de códigos e interligação elétrica e engenharia molecular (BOAVENTURA e JURKIEWICZ, 2009). Dentre as subestruturas de grafo que oferecem soluções para problemas aplicados, os caminhos se destacam especialmente pelo potencial associado aos problemas de trânsito, transporte e localização em sistemas discretos (BOAVENTURA NETTO, 2006).

Define-se um grafo $G=(X, F)$ como uma estrutura formada por um conjunto de $X$ de elementos chamados vértices ou nós e um conjunto $F$ de pares de arcos ou arestas, que pode ser representado graficamente por pontos (vértices) e linhas (arestas) unindo estes pontos (CAMPOS, 2012).

Um problema bastante comum envolvendo a teoria dos grafos é o problema de rota mais curta, ou caminho mínimo. Para cada arco de um grafo, define-se a distância que ele representa e/ou os custos ou tempos mínimos. O objetivo deste tipo de problema é encontrar o caminho mais curto entre dois nós (LISBOA, 2009).

Segundo Davis (2001), o problema do caminho mínimo se adapta a diversas situações práticas. Em roteamento, por exemplo, os nós do grafo podem ser modelados como cruzamentos, os arcos como vias, e os custos associados aos arcos correspondem distância percorrida ou ao tempo de trajeto, sendo a solução o caminho mais curto ou mais rápido entre dois pontos.

Oss algoritmo para a solução de problemas de caminho mínimo apresentados são: o algoritmo de Dijkstra, o algoritmo de Bellmann-Ford e o algoritmo de Floyd. Todos eles buscam encontrar as menores distâncias entre pontos, neste caso, os 
prédios localizados nas dependências da instituição para, em seguida, alocar os ecopontos, formando uma rede logística reversa da coleta do papel pós-consumo.

\subsubsection{Algoritmo de Dijkstra}

O algoritmo de Dijkstra foi proposto em 1959 e se tornou o mais famoso dos algoritmos para resolver problema de caminho mínimo de redes. Este algoritmo só pode ser trabalhado se os custos associados aos arcos forem positivos, pois geralmente os custos associados aos arcos são grandezas fisicamente mensuráveis. Por isso, o método de solução de problemas de caminho mínimo mais utilizado na prática é este algoritmo (DAVIS, 2001).

Boaventura \& Jurkiewicz (2009) definem que se algum dos arcos tiver valor negativo, o algoritmo de Dijkstra não garante um resultado correto, pois pode ocorrer que uma dada etapa este arco esteja unindo o vértice-base a um vértice já fechado. Neste caso, o novo custo deste vértice já fechado será menor que o anterior, o que invalida a afirmação de que o um vértice fechado não pode ter seu custo melhorado. A ideia do algoritmo é encontrar a menor distância entre dois pontos, um de origem e outro de destino, bem como os percursos correspondentes.

\subsubsection{Algoritmo de Bellmann-Ford}

O algoritmo de Bellmann-Ford trabalha com os arcos do grafo, ou seja, busca um arco após o outro em uma ordem dada, para observar se algum deles melhora algum caminho da origem até o vértice de chegada do arco e aceita arcos de valor negativo (BOAVENTURA \& JURKIEWICZ, 2009).

Segundo Campos (2012), o algoritmo de Bellmann-Ford é tratado como uma generalização do algoritmo de Dijkstra, que permite a utilização de arcos com valores negativos e que, a partir de uma pequena modificação, permite a existência de ciclos negativos. Contudo, nestes casos, o algoritmo não chega a uma solução ótima. Boaventura Netto (2006) reforça que o algoritmo de Bellmann-Ford não fecha os vértices. Assim, todos os valores podem ser revistos até o final. Com isso, é possível trabalhar com grafos contendo arcos de valor negativo desde que não exista circuito de valor negativo. 


\subsubsection{Algoritmo de Floyd}

O algoritmo de Floyd é um algoritmo que utiliza matrizes para determinar os caminhos mínimos entre todos os pares de nós da rede, realizando $n$ interações, que correspondem ao número de nós (CAMPOS, 2012).

Boaventura \& Jurkiewicz (2009) afirmam que este algoritmo, além de encontrar o caminho mais curto de cada vértice em relação aos demais, não é influenciado por valores negativos. O mesmo autor reforça ainda que o algoritmo de Floyd não "fecha" os vértices como algoritmo de Dijkstra. Com isso, o vértice pode ser reexaminado até o final das interações do algoritmo, na busca de novos caminhos.

A ideia básica deste algoritmo, conforme Campos (2009), consiste em verificar a cada iteração se a inclusão de um nó $\mathrm{k}$ intermediário no caminho de i para j pode reduzir o tamanho de um caminho já determinado. Cada iteração corresponde uma matriz $\mathrm{n} \times \mathrm{n}$ cujos valores são modificados utilizando uma fórmula de recorrência (eq. 2). Deste modo, trabalha-se com $K$ matrizes de $n \times n$, sendo $K=$ $1,2,3 \ldots$ n. Por sua vez, cada valor da matriz é definido como:

$$
d_{i j}^{k}=\min \left\{d_{i k}^{k-1}+d_{k j}^{k-1}, d_{i j}^{k-1}\right\}
$$

Onde, dijk representa o caminho entre os nós i e j na k - ésima matriz de iteração.

Inicialmente, é preciso adaptar a matriz de valores, chamada de D0, definindo os seguintes parâmetros para valores da matriz: Infinito $(\infty)$ para às posições dos arcos que não existe no grafo, assim o algoritmo não vai passar por eles; Nulos (valor zero) a diagonal principal, pois o custo é nulo quando não sair do lugar; e, os dos arcos, nas posições correspondentes aos arcos que existirem (BOAVENTURA \& JURKIEWICZ, 2009).

Após determinação da matriz D0 calcula-se D1 de D0 e D2 de D1, até obter Dn de Dn-1(Dn é a matriz final que apresenta os caminhos mínimos entre todos os nós da rede). Para esse método são feitas as seguintes observações, segundo o mesmo autor:

- Para $\mathrm{d}_{i i}{ }^{\mathrm{k}}=0$ para todo $i$ e para todo $K$, os elementos das matrizes não necessitam ser calculados;

Revista Produção Online, Florianópolis, SC, v.13, n. 4, p. 1543-1568, out./dez. 2013. 
- Os elementos da linha e da coluna $K$ da matriz $D^{k}$ são iguais ao da matriz $\mathrm{D}^{\mathrm{k}-1}$ quando $d_{i k}{ }^{k-1}=d_{i k}{ }^{k}$ e $d_{k i}{ }^{k-1}=d k i^{k}$ para todo $i=1,2 . . n$., isto ocorre devido o vértice/nó $K$ não pode ser um nó intermediário de um caminho que se inicia ou termina nele mesmo, desde que não existam ciclos negativos. Deste modo, em cada matriz $D^{k}$ somente $(n-1)(n-2)$ elementos que não estão nem na diagonal nem na $K$ - ésima linha e coluna precisam ser calculados.

Em seguida, estima-se outra matriz auxiliar, chamada de matriz de roteamento, para apoiar na identificação por onde passam os caminhos (BOAVENTURA \& JURKIEWICZ, 2009). Esta matriz permite a descrição do caminho mínimo entre cada par de vértices e consiste no princípio de que um vértice $K$

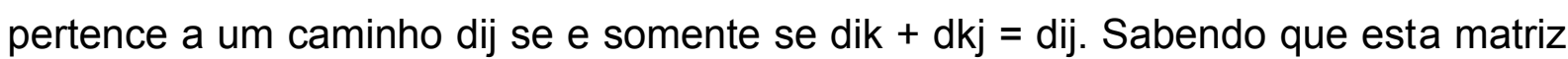
é formada pelos penúltimos vértices dos caminhos entre os pares de vértice do grafo e definido o elemento $\mathrm{K}$, tem-se:

$$
\begin{aligned}
& r_{i j}=K \text { (elemento da matriz de roteamento) } \\
& d_{i j}=? \\
& r_{i k}=\ldots . . r_{i k m}=i
\end{aligned}
$$

Portanto, o penúltimo vértice vai sendo substituído a cada caminho até que se chega ao nó inicial ido caminho procurado. Se for considerado que um caminho tem m nós intermediários, com início no penúltimo K, será alcançado o nó de origem ao encontrarmos o elemento $\mathrm{Km}$.

\section{METODOLOGIA}

Esta pesquisa é classificada, quanto a sua natureza, como aplicada, por propor um modelo de coleta para o papel pós-consumo da IFES. Segundo Silva \& Menezes (2005), a pesquisa aplicada "objetiva gerar conhecimentos para aplicação prática e dirigidos à solução de problemas específicos. Envolve verdades e interesses locais".

Quanto à abordagem, esta pesquisa é quantitativa, visto que, segundo Vieira (2010):

As pesquisas quantitativas são aquelas que se propõem a explicar, por meio de dados quantificáveis, as causas, as consequências e as inter-relações entre os fenômenos. Em geral, uma pesquisa quantitativa se pauta pela busca da comprovação ou da negação de uma hipótese assumida quando 
do delineamento do trabalho por meio da coleta, do levantamento de dados, a fim de que estes possam ser sistematizados com o objetivo de descobrir padrões e tendências que possam confirmar ou não essa hipótese. (VIEIRA, 2010, p.107).

Quanto aos objetivos, trata-se de uma pesquisa exploratória, tendo em vista a importância desse estudo para universidade, por aprimorar a aplicação de modelos de caminho mínimo em problemas logísticos reversos.

Conforme Gil (2002), estas pesquisas proporcionam uma maior familiaridade com o problema visando, principalmente, o aprimoramento de ideias. Ainda segundo o mesmo autor, a pesquisa envolve levantamento de bibliográfico, entrevistas com pessoas que tiveram experiências práticas com o problema pesquisado e análise de exemplos que estimulem a compreensão. No contexto deste trabalho, serviu para melhor esclarecer os assuntos abordados, conhecer melhor o problema estudado e desenvolver modelos propostos.

Quanto aos procedimentos técnicos, a pesquisa pode ser considerada um estudo de caso. Segundo Gil (2002, p.54), "[...] o estudo de caso costuma ser utilizado tanto como estudo-piloto para esclarecimento do campo da pesquisa em seus múltiplos aspectos quanto para a descrição de síndromes raras".

No intuito de alcançar o objetivo proposto, o desenvolvimento do presente artigo seguiu as etapas apresentadas na Figura 2.

Figura 2 - Etapas do trabalho

\begin{tabular}{|c|c|}
\hline $1^{\circ}$ Etapa & Caracterização do objeto de estudo \\
\hline $2^{\circ}$ Etapa & $\begin{array}{l}\text { Análise da sistemática atual de coleta da } \\
\text { instituição }\end{array}$ \\
\hline $3^{\circ}$ Etapa & Proposição da nova sistemática de coleta \\
\hline $4^{\circ}$ Etapa & Simulação dos cenários \\
\hline
\end{tabular}

Fonte: Elaborado pelos autores (2012)

A primeira etapa caracteriza o escopo do estudo e define uma estimativa de geração de papel em função do consumo da unidade administrativa. Foram coletados dados referentes ao número e a identificação das unidades geradoras do papel pós-consumo junto ao almoxarifado e a unidade da Xerox da IFES, bem como o consumo de papel de cada unidade. 
Para a obtenção dos dados de descarte do papel pós-consumo da instituição, foram coletados dados das tabelas de amostras de resíduos sólidos classe II, utilizada por Coelho (2010) em seu estudo de dimensionamento de sistema para recebimento, armazenamento e tratamento de resíduos sólidos da universidade. Em seguida, estimou-se o percentual de descarte para cada unidade da IFES.

Por fim, por meio do setor de infraestrutura da universidade, foi possível ter acesso à planta baixa atual da universidade, sendo realizadas as medições das distâncias entre as unidades geradoras e os possíveis ecopontos, e entre os ecopontos e o centro de reciclagem (inativo atualmente).

A segunda etapa da pesquisa se consistiu da análise de como a coleta era realizada. Esta fase se faz necessário para analisar os possíveis pontos de melhoria no processo de coleta. Em seguida, foi formulado um grafo a partir dos dados de entrada, que representou os prédios e suas respectivas distâncias entre eles, bem como os sentidos das vias a ser seguida pelos carros que fazem este transporte.

$\mathrm{Na}$ terceira etapa foram elaborados dois modelos de localização adequados às necessidades e condições do caso, sendo o primeiro em função da demanda de papel pós-consumo descartado pelas unidades e o segundo em função do atendimento das unidades geradoras, levando em consideração o caminho mínimo.

Para tanto, optou-se em estabelecer o modelo de localização através do algoritmo de Floyd, dado ele ser o método que mais se ajusta ao problema de implantação de ecopontos dentre as unidades geradoras. Como restrição para ambos os modelos foi adotada a distância de caminhada do colaborador responsável pela coleta do papel até o ecoponto mais próximo.

\section{DISCUSSÃO DOS RESULTADOS}

\subsection{Caracterização do objeto de estudo}

O presente estudo foi realizado no campus central da IFES em questão, situado no município de Mossoró, no estado do Rio Grande do Norte. Este campus é cortado ao meio pela BR110, definindo os lados leste e oeste. A Figura 3 ilustra a delimitação da área de estudo.

Revista Produção Online, Florianópolis, SC, v.13, n. 4, p. 1543-1568, out./dez. 2013. 
Figura 3 - Delimitação da área de estudo

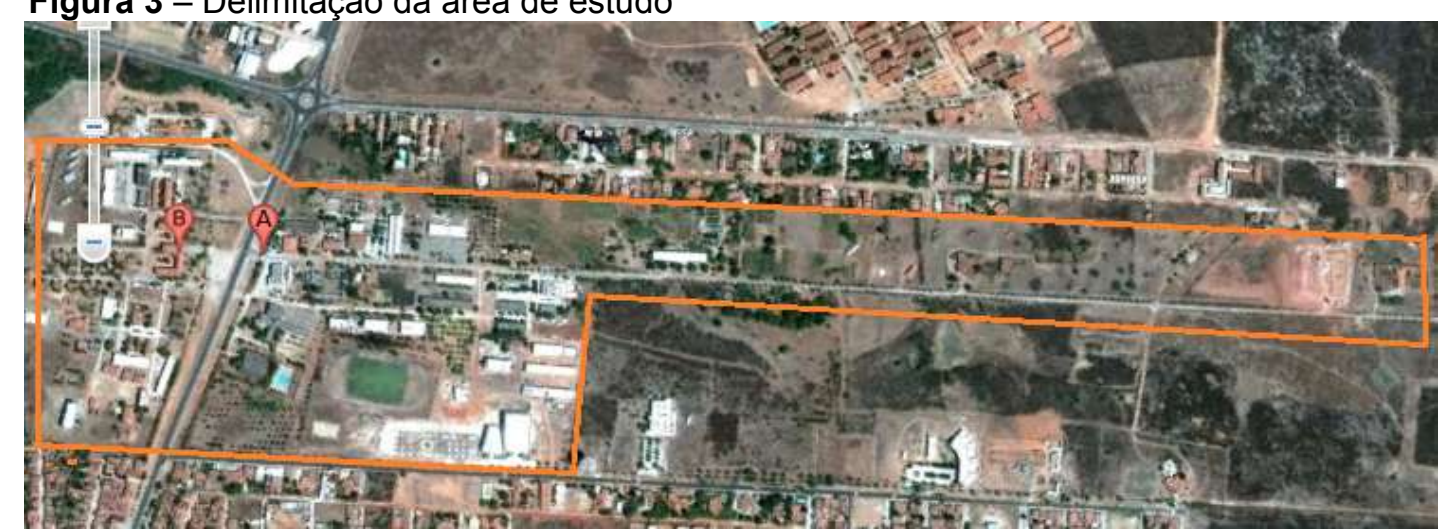

Fonte: Adaptado do Google Maps. Disponível em: <http://maps.google.com.br/?hl=pt-BR>

Como se pode observar na Figura 3, os lados leste e oeste estão indicados pelas letras $A$ e $B$, respectivamente. Atualmente, o campus central desta IFES oferece 23 cursos de graduação e 10 cursos de pós-graduação.

A quantidade de papel pós-consumo gerado por cada unidade foi estimado devido à inexistência de dados oficiais (existência de dados de demanda e não existência de dados de descarte).

Assim, a demanda por papel das unidades foi obtida através da consulta dos dados dos setores de almoxarifado e reprografia, pois essa última fornece resmas de papeis para algumas das unidades. Os dados coletados são referentes ao ano de 2011 e foram estratificados segundo o consumo de cada unidade. Em seguida, foi criada uma planilha apresentando a demanda de cada uma das 53 unidades por resmas de papel.

A partir destes dados, foi possível calcular a quantidade de resmas demandadas durante todo o ano de 2011, exatos 2.318 unidades, o equivalente a $5.424,12 \mathrm{Kg}$, aproximadamente. Considerou-se que uma resma equivale a 2,34 quilogramas (CRATO, 2003).

O procedimento para estimar a quantidade de papel pós-consumo da universidade seguiu o mesmo procedimento adotado por Coelho (2010) para estimar a média ( $\mathrm{kg} / \mathrm{dia}$ ) das amostras de resíduos sólidos classe II coletados na IFES, expresso por uma média de 2,75 quilogramas de papel descartado por dia na universidade, o equivalente a 990 quilogramas ao ano, considerando que o mês composto de 30 dias e a existência de arquivamento de papel nas unidades.

A partir dessas informações e considerando a existência de uma proporcionalidade entre a quantidade de demanda total e a quantidade de descarte Revista Produção Online, Florianópolis, SC, v.13, n. 4, p. 1543-1568, out./dez. 2013. 
total do papel na instituição, a Tabela 1 apresenta a equação para calcular a estimativa de papel gerado por cada unidade.

Tabela 1 - Proporção estabelecida para estimativa de descarte de papel pelas unidades

\begin{tabular}{|c|c|c|c|}
\hline & Demanda (kg/ano) & & Descarte (Kg/ano) \\
\hline IFES & $5.414,76$ & & 990 \\
\hline Unidade i & 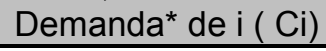 & $\longleftrightarrow$ & Descarte em i ( Di ) \\
\hline
\end{tabular}

*definido como consumo.

Fonte: Elaborado pelos autores (2012).

Neste sentido, pela regra proporcional estabelecida pela Tabela 1, tem-se:

$$
\mathrm{Di}=\frac{990 \mathrm{Ci}}{5.424,12}=0,1825 \mathrm{Ci}
$$

A quantidade de descarte de papel pós-consumo anualmente em cada unidade da UFERSA deve ser 0,1825 vezes o valor do demanda de papel que existe na mesma, conforme a Equação 1. A partir deste dado, a estimativa de descarte da quantidade de papel pós-consumo gerados ao ano por cada unidade pôde ser obtida. A Figura 4 ilustra o consumo acumulado das unidades.

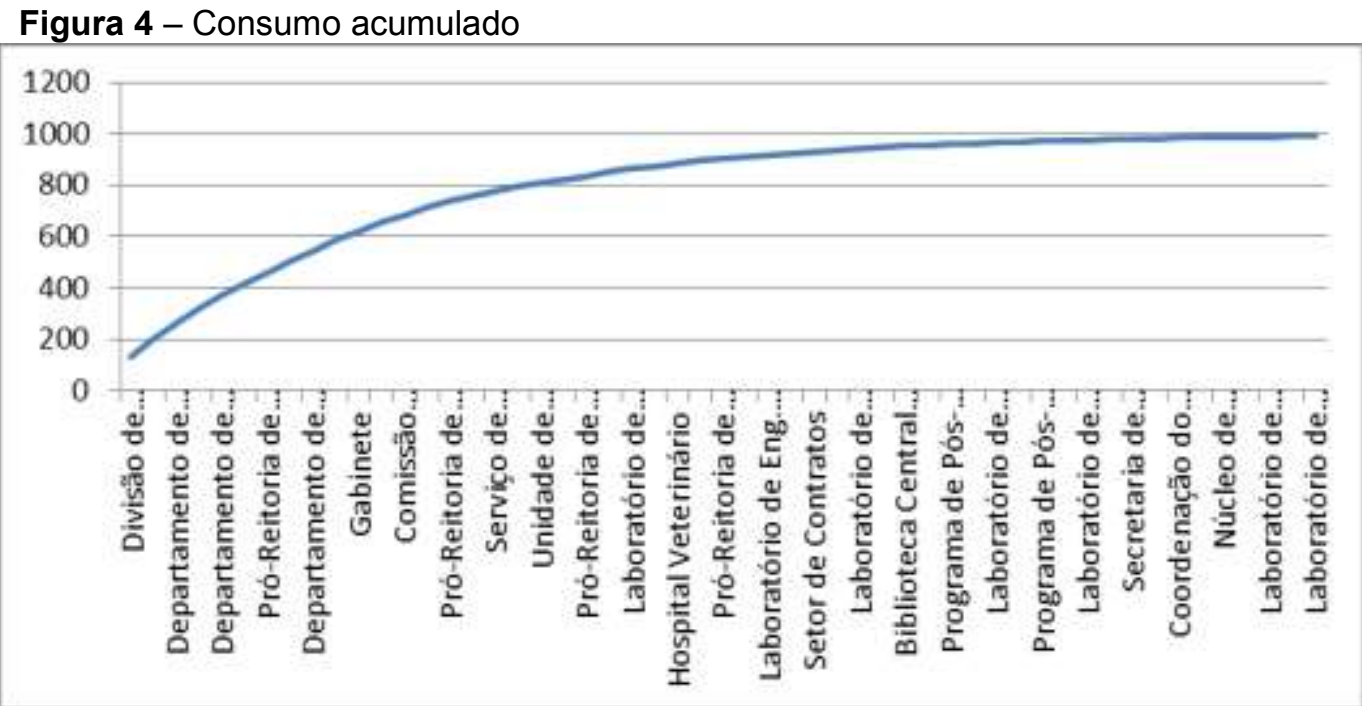

Fonte: Elaborado pelos autores (2012)

\subsection{Análise da sistemática atual de coleta}

A análise da sistemática atual de coleta consiste na criação dos grafos orientados, composto por vértices e arestas ou arcos. Os vértices se remetem aos prédios ou unidades geradoras de papel inservível e as arestas às distâncias entre as unidades.

Revista Produção Online, Florianópolis, SC, v.13, n. 4, p. 1543-1568, out./dez. 2013. 
Primeiramente, foram coletados os dados referentes à localização dos prédios e as distâncias existentes entre eles, tomando-se como referência a planta baixa atualizada da IFES. A partir dessas informações, com o auxilio do programa computacional Grafos v.1.3.4, foi possível construir o um Grafo orientado, ilustrado na Figura 5. Foram definidas algumas premissas para o desenvolvimento do modelo:

- Considerou-se somente o tempo total de coleta do veículo como a variável condicionadora para a escolha do modelo, dada a falta de dados para a construção do custo de coleta;

- O ponto de armazenagem temporário do resíduo coletado é o mesmo dimensionado na pesquisa de Coelho (2010), denominado como Abrigo de Resíduos, onde o órgão municipal faz a coleta externa dos resíduos não recicláveis que serão dispostos no aterro sanitário local, como também à associação recicladora responsável pela coleta externa de material reciclável.

- Os ecopontos não são fixos: o modelo definirá os "melhores locais", considerando as restrições impostas, para se instalar os ecopontos. Para cada local candidato (prédio) somente um ecoponto pode ser instalado;

- Aspectos relacionados à capacidade dos veículos e a capacidade de armazenagem dos ecopontos não foram considerados, pois o volume de papel descartado não é suficiente para ultrapassar os limites dos mesmos, tendo em vista que as coletas são realizadas diariamente, nos períodos matutino e vespertino;

- Considerou-se que todas as rotas que ligam os prédios da estrutura da universidade são plenamente acessíveis e comportam o deslocamento do veículo escolhido para realizar as rotas de coleta. 
Figura 5 - Grafo orientado das unidades geradoras de papel pós-consumo.

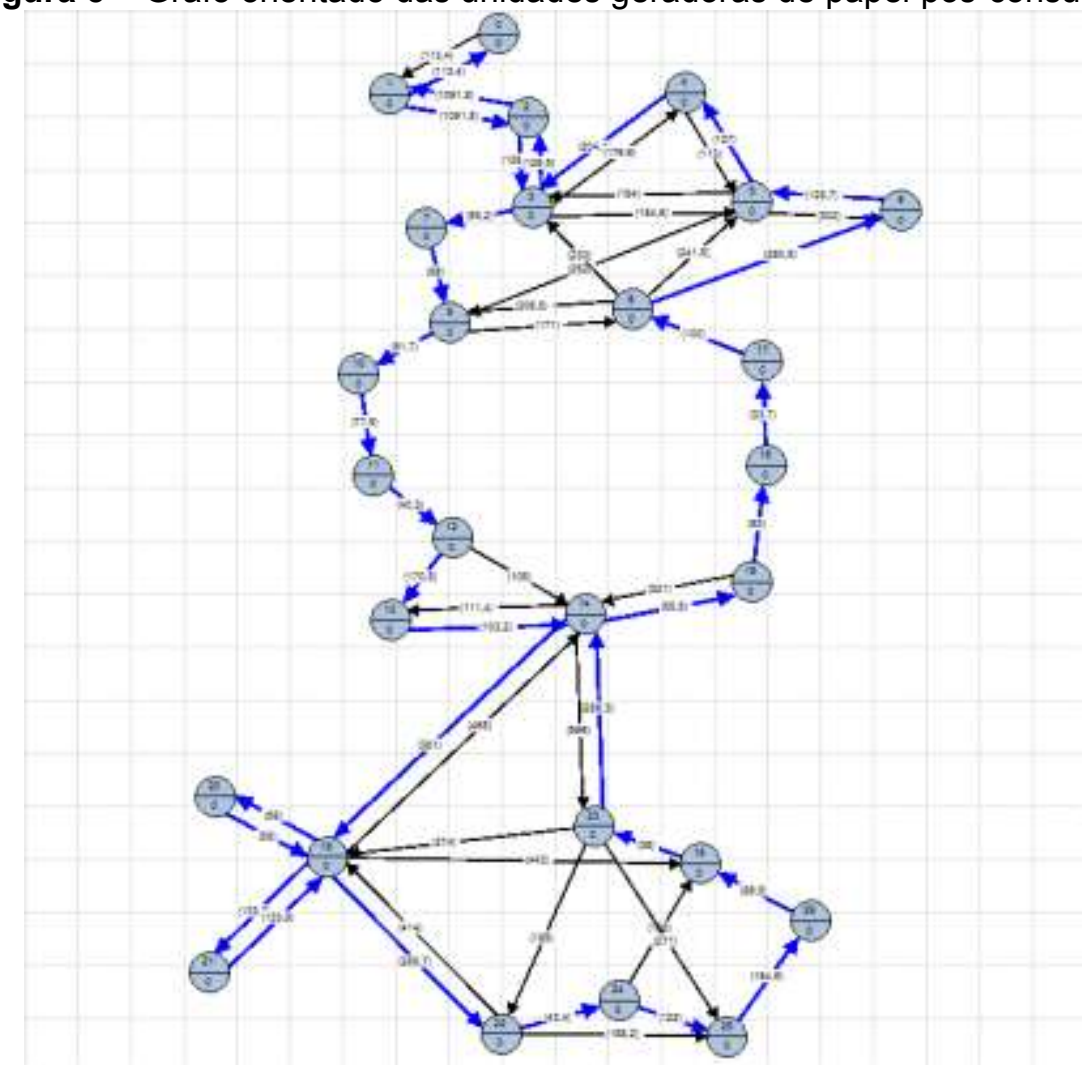

Fonte: Elaborado pelos autores (2012)

Na Figura 5, cada vértice representa um prédio da instituição, com exceção dos vértices 0 e 7 , onde está localizado o ponto de armazenamento temporário do papel pós-consumo coletado, e onde estão localizados dois prédios dispostos frontalmente, respectivamente.

As arestas representam as distâncias de um prédio em relação a outro, bem como as possíveis ligações entre eles, isto é, os possíveis caminhos para ir de um prédio para outro, sendo que as setas seguem o sentido das vias de acordo com projeto atual da universidade. As arestas na cor azul ilustram a rota seguida pelo transporte que faz a coleta do resíduo (papel pós-consumo) desde que atendimento a todos os vértices (prédios), tendo em vista que este modelo não possui alocação de ecopontos.

Foram desenvolvidos dois modelos com diferentes localizações de ecopontos: o primeiro baseou-se na implantação de ecopontos nos prédios de maior descarte e o segundo contemplou a implantação dos ecopontos baseado no maior número de prédios atendidos. Para ambos os modelos propostos neste trabalho foram considerados os seguintes aspectos:

Revista Produção Online, Florianópolis, SC, v.13, n. 4, p. 1543-1568, out./dez. 2013. 
- Uma distância máxima de 150 metros de caminhada (LADEIRA et al., 2007), do ecoponto escolhido aos demais prédios. Esse valor foi adotado com base nas distâncias entre paradas de ônibus para áreas com aclives, tendo em vista que o papel descartado pelas unidades será transportado até o ecoponto mais próximo por pessoas.

- Adotou-se o tempo médio de espera do transporte coletor de 38 segundos para cada ecoponto atendido. Esse valor foi obtido através de observação da equipe de coleta de lixo, formada por um motorista e três coletores de uma empresa terceirizada pela universidade, responsável por toda limpeza do campus.

- Para a velocidade do transporte coletor, adotou-se uma velocidade média de $20 \mathrm{~km} /$ hora para as distâncias percorridas entre os ecopontos. Esse valor está de acordo com a velocidade máxima permitida de $30 \mathrm{~km} / \mathrm{hora}$ para trafegar nas vias da IFES.

- Nas arestas ou arcos, as setas são únicas e de duplo sentido nas ligações dos prédios, tendo em vista que o papel pós-consumo do prédio é transportado por pessoas até o ecoponto mais próximo, sem obedecer aos sentidos das vias. Ressalta-se que as setas excluídas do modelo base são aquelas de maior distância entre os prédios quando há mais de uma possibilidade para ir de um prédio a outro.

- O Tempo Total ( Tt ) de coleta foi concebido da seguinte forma: Tempo percorrido (Tp) pelo transporte somado com o Tempo de espera (Te) para coletar o resíduo multiplicado pela Quantidade de ecopontos (Qe). Portanto:

$$
T t=T p+(T e \times Q e)
$$

- Para a medição do tempo percorrido, não foram consideradas as interferências externas como, por exemplo, a passagem de um pedestre ou veículo nas vias, um semáforo dentre outros, sendo parado o cronômetro nesses instantes.

Considerando os pontos supracitados, é possível calcular o tempo total requerido para coletar o papel pós-consumo do modelo base, em que não existe Revista Produção Online, Florianópolis, SC, v.13, n. 4, p. 1543-1568, out./dez. 2013. 
ecopontos e o veículo passa por todas as unidades geradoras. Diante disto, o tempo gasto para percorrer todos os prédios é de 24 minutos e 52 segundos, com tempo de espera de 38 segundos para cada parada. Portanto, o tempo total para coletar o papel pós-consumo, conforme a Equação 2, é de 41 minutos e 20 segundos.

\subsection{Proposição da nova sistemática de coleta}

\subsubsection{Proposição 1 - Modelo de coleta com a implantação de ecopontos baseado na geração de papel pós-consumo das unidades geradoras}

Este cenário se propõe a avaliar o desempenho da rede logística com base na localização de ecopontos coletores a partir do descarte feito pelas unidades geradoras de papel pós-consumo, de maneira que esses pontos de coleta atendam todos os prédios em estudo. Para definição dos ecopontos neste modelo, foram realizadas as seguintes etapas:

- $1^{\circ}$ etapa: Foram coletados os dados referentes à demanda de descarte de papel pós-consumo de cada vértice correspondente. Em seguida, eles organizados em ordem decrescente, ou seja, do vértice de maior descarte de papel para o menor.

- $2^{\circ}$ etapa: Foi realizada a verificação da ordem sequencial dos vértices, quais unidades são atendidas, considerando a distância limite de 150m. No mesmo instante, com a identificação da unidade atendida para aquele vértice, a mesma é desconsiderada como possível ecoponto. Dessa forma, foi possível determinar todos os ecopontos coletores.

- $3^{\circ}$ etapa: Observaram-se quais ecopontos atendiam as unidades em comum.

- $4^{\circ}$ etapa: Foram determinadas as unidades correspondentes a cada ecoponto escolhido, através da verificação da menor distância entre a unidade e os ecopontos analisados.

Deste modo, foram escolhidos 13 ecopontos coletores de papel pós-consumo num total de 26 vértices, que está indicada na cor vermelha, conforme ilustrado na Figura 6, a seguir. 
Determinada a localização dos ecopontos, o passo seguinte foi a medição do tempo total de coleta do modelo proposto no primeiro cenário, sendo necessário um veículo e um cronômetro para medir todo o percurso ou rota, obedecendo os sentidos das vias. A rota a ser seguida pelo veículo deve atender todos os ecopontos, percorrendo as menores distâncias entre eles. Da garagem se inicia o caminho percorrido, localizado também no vértice 1. Em seguida, o veículo passa por todos os demais ecopontos e termina sua rota no Abrigo Temporário, onde são depositados o resíduos (vértice 0 ). Esse trajeto pode ser visualizado na cor vermelha (Figura 6).

O tempo gasto para percorrer os 13 ecopontos até o Abrigo Temporário foi de 21 minutos e 43 segundos, com o tempo de espera é de 38 segundos para cada ponto coletor. Assim, pode-se determinar o Tempo Total de acordo com a Equação (2).

O tempo total foi de 29 minutos e 57 segundos, representando o Tempo Total percorrido pelo veículo para coletar o papel pós-consumo descartado pelas unidades geradoras. Desta forma é possível constatar que, em relação ao modelo base, houve uma redução de aproximadamente $29 \%$ no tempo total de coleta. 
Figura 6 - Ecopontos implantados com base no descarte de papel pelas unidades

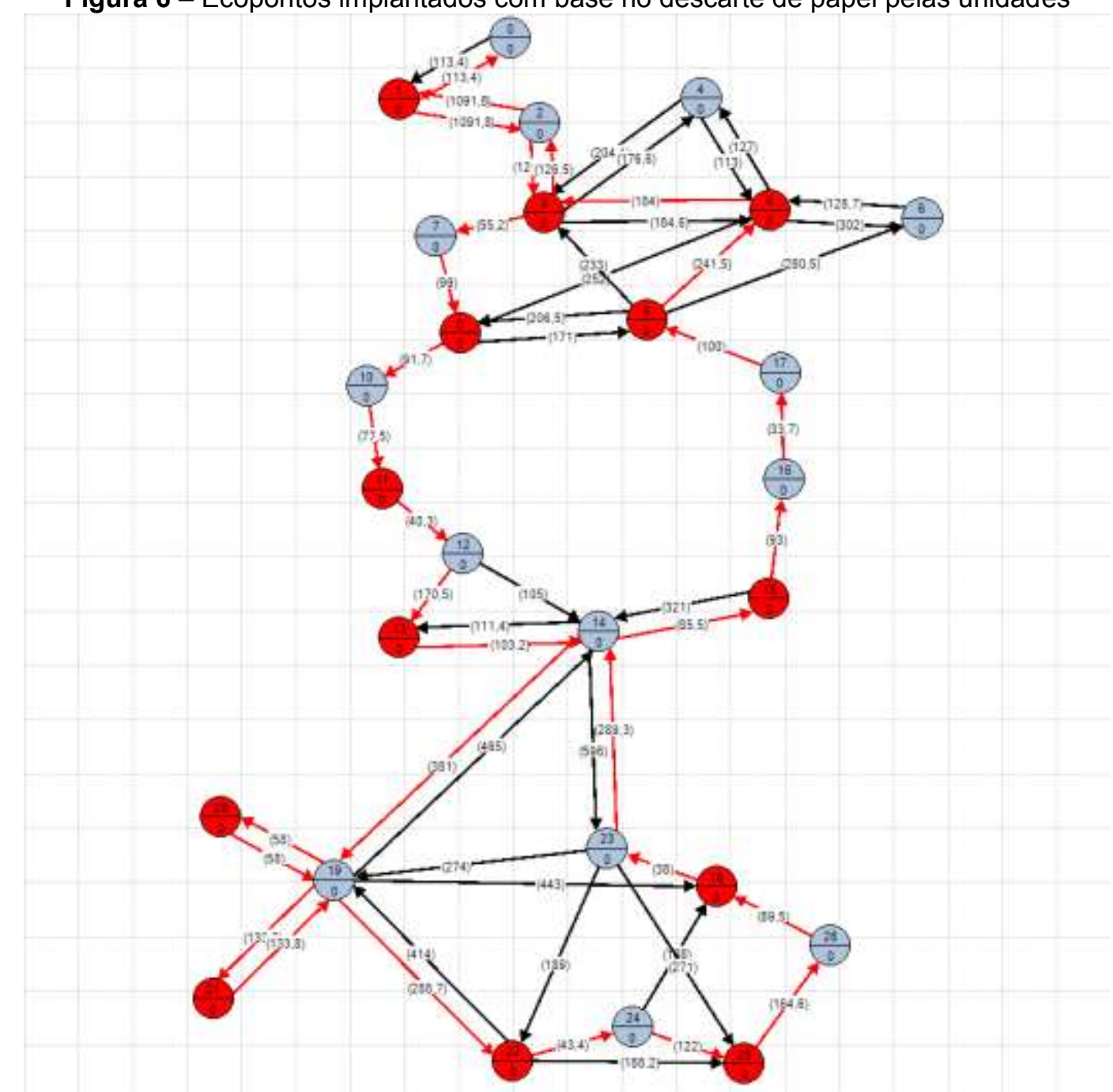

Fonte: Elaborado pelos autores (2012)

\subsubsection{Proposição 2 - Modelo de coleta com a implantação de ecopontos baseado no atendimento máximo das unidades geradoras.}

Neste cenário, propõe-se avaliar o desempenho da rede logística com base na localização de ecopontos coletores que possam atender o maior número de unidades geradoras de papel pós-consumo.

Assim, foi utilizado o algoritmo de Floyd, que é o mais adequado na abordagem do problema em questão, pois o objetivo é encontrar o caminho mínimo de cada vértice (prédio) para os demais. Os ecopontos neste modelo foram escolhidos de acordo com as etapas a seguir: 
- $1^{\circ}$ etapa: Foram encontrados os caminhos mínimos de cada vértice para todos os outros, através do algoritmo de Floyd com o auxílio do programa computacional Grafos-v.1.3.4.

- $2^{\circ}$ etapa: Por meio de um algoritmo no programa computacional $\mathrm{C}++$ criado por Fontes (2012), foi verificado na matriz de distâncias mínimas para cada vértice (linha da matriz), quantos vértices estão abaixo de 150 metros daquele vértice da linha da matriz.

- $3^{\circ}$ etapa: A partir daquela linha com maior quantidade de valores abaixo de 150 metros foram determinados os ecopontos coletores. Esse processo foi adotado até que os ecopontos atendessem todos os vértices.

- $4^{\circ}$ etapa: Foi certificado se um ecoponto atendia um vértice já atendido por outro ecoponto que, se confirmado, verificava-se qual ecoponto com a menor distância daquele vértice. Assim, o vértice permanecia na lista de pontos atendidos por aquele ecoponto com a menor distância.

Os ecopontos coletores obtidos foram os vértices 1, 3, 5, 10, 14, 16, 19, 23 e 24 , totalizando 9 ecopontos, os quais atendem todos os outros 17 vértices com as mínimas distâncias possíveis. Na cor verde, estão localizados os pontos coletores de papel pós-consumo descartado pelas unidades geradoras (Figura 7).

Por meio da definição da localização dos ecopontos, determinou-se o tempo total do modelo proposto. A rota do veículo segue o mesmo princípio do modelo proposto na proposição 1 , ou seja, o trajeto começa na garagem dos transporte (vértice 1) da IFES passa por todos os ecopontos escolhidos no modelo e termina no Abrigo Temporário (vértice 0) de resíduo, percorrendo as mínimas distâncias entre os pontos de coleta. As setas na cor verde indicam o percurso realizado pelo veículo.

Para percorrer todo o trajeto com 9 ecopontos, o veículo gastou o tempo de 15 minutos e 5 segundos. $O$ tempo de espera adotado é de 38 segundos para cada ecoponto. Da mesma forma, o Tempo Total de coleta do papel descartado das unidades geradoras pode ser obtido de acordo com a Equação (2). Feitas as alterações nos parâmetros de tempo percorrido e o número de ecopontos, observase uma nova solução para o modelo cuja equação apresentou um valor de 20 
minutos e 47 segundos, representando o Tempo Total percorrido pelo veículo para coletar o papel pós-consumo descartado pelas unidades geradoras.

A partir das informações, constata-se que houve uma redução no tempo total de coleta do papel pós-consumo, passando de 29 minutos e 57 segundos para 20 minutos e 47 segundos, representando uma redução de $30,6 \%$ no tempo total de coleta papel pós-consumo. Esse valor é o resultado da otimização da rede logística exposta no modelo, eliminando quatro ecopontos, o que diminuiu as distâncias percorridas bem como o tempo gasto para percorrer todo o trajeto entre os ecopontos.

Se projetado para as condições iniciais do projeto, o ganho de 9 minutos e 10 segundos a cada coleta é multiplicado por dois, já que o recolhimento é realizado diariamente e durante dois períodos, ou seja, o ganho diário é de 18 minutos e 20 segundos. Isso significa que a cada três coletas realizadas, observa-se uma economia de uma coleta, reduzindo os gastos envolvidos em toda logística reversa como, por exemplo, combustível e manutenção, como também prolongar a vida útil do veículo e das ferramentas utilizadas. Além disso, é possível realocar os recursos empregados para outras atividades de interesse das partes integrantes, isto é, a empresa terceirizada e/ou universidade. 
Figura 7 - Ecopontos implantados com base no maior atendimento das unidades

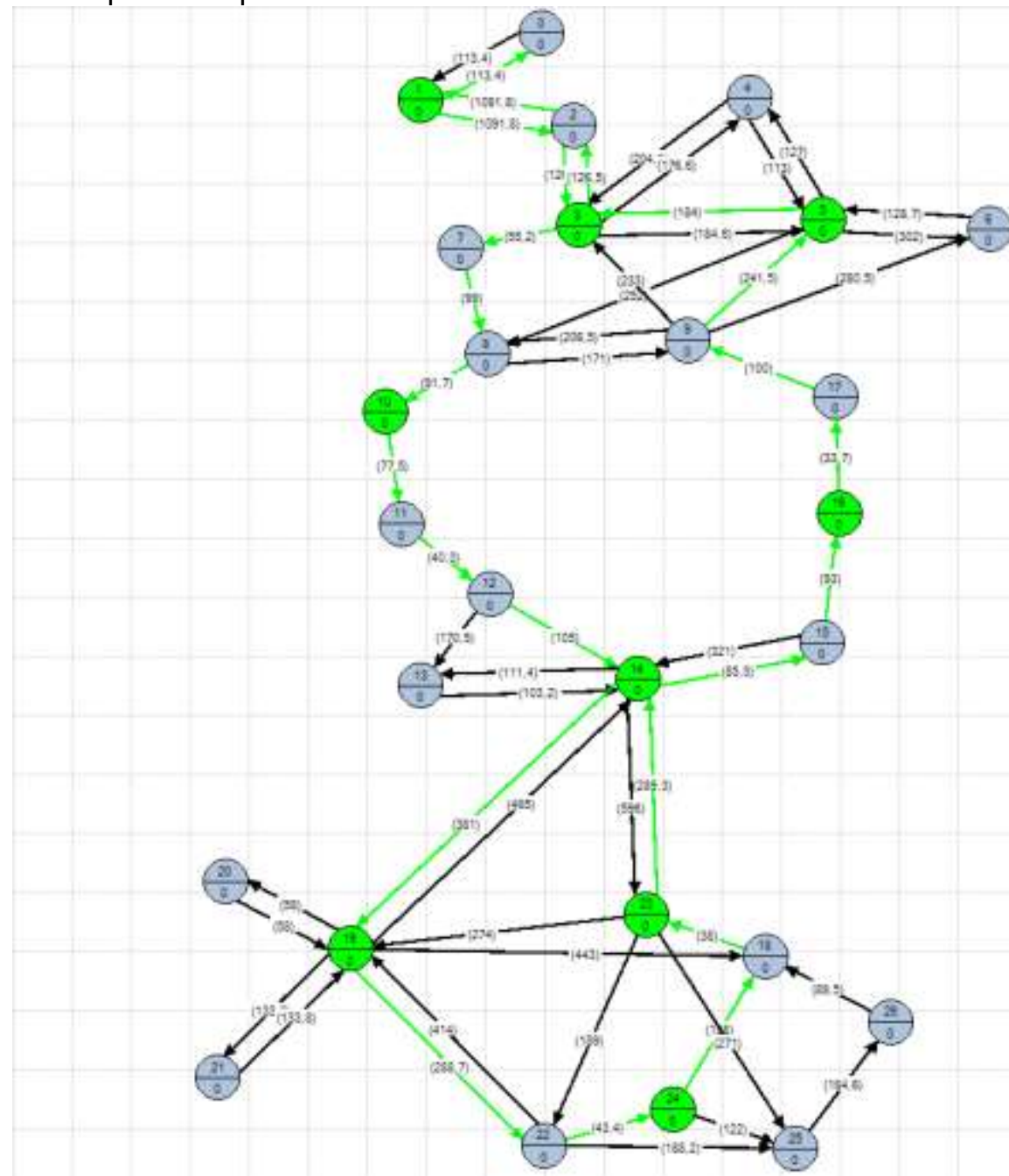

Fonte: Elaborado pelos autores (2012)

A Tabela 2 sintetiza os resultados obtidos.

Tabela 2 - Tempos totais obtidos no trabalho

\begin{tabular}{cc}
\hline Cenários & Tempo Total de coleta \\
\hline Modelo atual & 41 minutos e 20 segundos \\
Proposição 1 & 29 minutos e 57 segundos \\
Proposição 2 & 20 minutos e 47 segundos \\
\hline
\end{tabular}

Fonte: Elaborado pelos autores (2012)

\section{CONSIDERAÇÕES FINAIS}

Este trabalho teve como objetivo propor um modelo de coleta para o papel pós-consumo gerado pelas unidades da IFES em estudo. A Tabela 3 apresenta a matriz de consolidação de tempos oriundos de cada modelo. A matriz expõe, por exemplo, que houve uma redução de $29 \%$ no resultado do tempo total obtido no Revista Produção Online, Florianópolis, SC, v.13, n. 4, p. 1543-1568, out./dez. 2013. 
modelo atual para o resultado concebido na Proposição 1; do modelo atual para a Proposição 2 houve uma redução de 49,7\%. Comparando-se a Proposição 1 com a Proposição 2, pode-se observar que a proposição 2 é melhor que a 1.

Tabela 4 - Consolidação dos tempos em porcentagem entre os cenários

\begin{tabular}{lccc}
\hline & Modelo atual & Proposição 1 & Proposição 2 \\
\hline Modelo atual & $\mathrm{x}$ & $-29 \%$ & $-49,7 \%$ \\
Proposição 1 & $\mathrm{X}$ & $\mathrm{X}$ & $-30,6 \%$ \\
Proposição 2 & $\mathrm{X}$ & $\mathrm{x}$ & $\mathrm{x}$ \\
\hline
\end{tabular}

Fonte: Elaborado pelos autores (2012)

Os resultados obtidos com os modelos foram satisfatórios quanto à alocação de ecopontos, otimizando os tempos totais de coleta de papel pós-consumo, através de uma melhor roteirização do percurso de coleta.

Assim, este trabalho contribuiu de forma satisfatória para a solução do problema de transporte no canal reverso do papel pós-consumo. O modelo proposto diminui consideravelmente os tempos totais de coleta do resíduo (papel), otimizando assim, a utilização dos recursos envolvidos neste processo.

Esse trabalho tem potencial para servir de base para outras instituição de ensino que também buscam aplicar um modelo estruturado de gerenciamento e coleta de resíduos.

\section{REFERÊNCIAS}

AITKEN, J. e HARRISON, A. Supply governance structures for reverse logistics systems. International Journal of Operations \& Production Management, v. $33 \mathrm{n}$. 6, p. 745-764, 2013.

BAI, C. e SARKIS, J. Flexibility in reverse logistics: a framework and evaluation approach. Journal of Cleaner Production, v.47, p. 306-318, 2013.

BARBIERI, J. C.; DIAS, M. Logística Reversa como instrumento de programas deprodução e consumo sustentáveis. Revista Tecnologística, São Paulo, v. 6, n. 77, p. 58-69, 2002.

BOAVENTURA NETTO, P. O. Grafos: Teoria, Modelos, Algoritmos. 4. ed. São Paulo: Edgar Blucher, 2006.

BOAVENTURA NETTO, P. O. e JURKIEWICZ, S. Grafos: Introdução e prática. São Paulo: Edgar Blucher, 2009. 
CAMPOS, V. B. G. Algoritmos para resolução de problemas em redes.

Disponível em: <http://aquarius.ime.eb.br/ webde2/prof/vania/apostilas/Apostila-

Redes.pdf>. Acesso em: 26 de maio de 2012.

CHAVES, G. L. D. e ALCÂNTARA, R. L. C. Logística Reversa: uma análise da evolução do tema através de revisão da literatura. ENCONTRO NACIONAL DE ENGENHARIA DE PRODUÇÃO - ENEGEP, 29,. 2009. Salvador - BA, 2009.

COELHO, D. C. L. Dimensionamento de sistema para recebimento, armazenamento e tratamento de resíduos sólidos da Universidade Federal Rural do Semi-Árido, campus Mossoró-RN. 2010.72f. Monografia (Graduação em Engenharia Agrícola e Ambiental). Departamento de Ciências Ambientais e Tecnológicas, Universidade Federal Rural do Semi-Árido. Mossoró, 2010.

DAVIS, C. Caminho mínimo em redes. Disponível em: < http://mundogeo.com/blog/2001/04/01/caminho-minimo-em-redes/>. Acesso em: 26 de junho de 2012.

DEKKER, R. Reverse logistics: quantitative models for closed-loop supplychains. Berlin: Springer-Verlag, 2004.

DIAS, R. Gestão ambiental: responsabilidade social e sustentabilidade. São Paulo: Atlas, 2006.

GRABRIELE, P. D., TREINTA, F. T., FARIAS FILHO, J. R., SOUZA, M. C., TSCHAFFON, P. B. e BRANTES, S. R. Sustentabilidade e vantagem competitiva estratégica: um estudo exploratório e bibliométrico. Revista Produção Online, v.12, n. 3, p. 729-755, 2012.

GIL, A. C. Como elaborar projetos de pesquisa. 4. ed. São Paulo: Atlas, 2002.

GODOY, M. R. B. Dificuldades para aplicar a Lei da Política Nacional de Resíduos Sólidos no Brasil. Caderno de Geografia, v.23, n.39, 2013.

GOODLAND, R. e LEDOC, G. Neoclassical economics and principies of sustainable development.EcologicalModelling, 38, 1988.

GUARNIERI, P. Logística Reversa: em busca do equilíbrio econômico e ambiental. - 1.ed. - Recife: Clube de Autores, 2011.

IDEC. Serviço: ambiente. O lado escuro do papel. Disponível em: <http://www.idec.org.br>. Acesso em: 10 de julho de 2012.

KIPPER, L. M., MÄHLMANN, C. M.; RODRIGUEZ, A. L. Ações estratégicas sistêmicas visando à integração da cadeia produtiva e de reciclagem de plásticos. Revista Produção Online, v.9, n.4, 2009. 
LADEIRA, M. C. L.; BOCKLAGE, M. C. O.; ARAÚJO, A. M.; MICHEL, F. D. Critérios de alocação das paradas de ônibus em Porto Alegre. Disponível em:<http://www.anpet.org.br/ssat/interface/content/autor/trabalhos/publicacao/2007/1 85_CT.pdf>. Acesso em: 18 de julho de 2012.

LEITE, P. R. Logística Reversa: meio ambiente e competitividade. 2. ed. São Paulo: Pearson Prentice Hall, 2009.

LISBOA, E. F. A. Pesquisa operacional. Rio de Janeiro, 2002. (Apostila).

NOVAIS, A. G. Logística e gerenciamento da cadeia de distribuição. Rio de Janeiro: Campus, 2001.

ROGERS, D. S. e TIBBEN-LEMBKE, R. S. Going Backwards: reverse logistics trends and practices. University of Nevada, Reno Center for Logistics Management. Reverse LogisticsExecutiveCouncil, 1998. Disponível em:

$<$ http://www.rlec.org/reverse.pdf $>$. Acesso em: 13 de março de 2012.

SELLITTO, M. A., KADEL JR., N., BORCHARDT, M., PEREIRA, G. M. E DOMINGUES, J. Coprocessamento de cascas de arroz e pneus inservíveis e logística reversa na fabricação de cimento. Revista Ambiente e Sociedade, v.16, n.1, 2013.

SELLITTO, M. A., BORCHARDT, M., PEREIRA, G. M. e PACHECO, D. A. J. Gestão da cadeia de suprimentos verde: quadro de trabalho. Revista Produção Online, v.13, n. 1, p. 351-374, 2013.

SILVA, E. L.; MENEZES, E. M. Metodologia da pesquisa e elaboração de dissertação. 4. ed. rev. atual. Florianópolis: UFSC, 2005.

SOUZA, S. F. e FONSECA S. U. L. Logística reversa: oportunidades para redução de custos em decorrência da evolução do fator ecológico. Disponível em: <http://www.ead.fea.usp.br/semead/11semead/resultado/trabalhosPDF/87.pdf>. Acesso em: 10 de julho de 2012.

VIEIRA, J. G. S. Metodologia de pesquisa científica na prática. Curitiba: Fael, 2010.

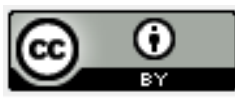

Artigo recebido em 29/01/2013 e aceito para publicação em 16/11/2013. 